\title{
Immature Granulocytes in Peripheral Blood Increased
}

National Cancer Institute

\section{Source}

National Cancer Institute. Immature Granulocytes in Peripheral Blood Increased. NCI

Thesaurus. Code C36215.

The presence of an increased number of granulocytic leukocytes, indicating an earlystage response to infection, inflammation, or neoplastic process. 